\title{
THE ASSOCIATION BETWEEN EDUCATIONAL ACHIEVEMENTS, CAREER ASPIRATIONS, ACHIEVEMENT MOTIVES AND ORAL HYGIENE BEHAVIOR AMONG DENTAL STUDENTS OF UDAIPUR, INDIA
}

\author{
Kailash Asawa ${ }^{1}$, Pulkit Chaturvedi ${ }^{1}$, MridulaTak ${ }^{1}$, Ramesh Nagarajappa $^{2}$, Nagesh \\ Bhat $^{1}$, Salil Bapat ${ }^{1}$, Vivek Gupta ${ }^{1}$, Sagar Jalihal ${ }^{1}$
}

\begin{abstract}
BACKGROUND: There are several factors which influence oral hygiene behavior of an individual. Educational achievements, career aspirations and achievement motives of individuals are some of those factors. The objective of this study was to investigate whether educational achievements, career aspirations and achievement motives have associations with oral hygiene behavior among dental students of Udaipur, India.

METHODS: A descriptive cross-sectional study was conducted among all (n=200) $1^{\text {st }}$ year dental students from all dental colleges of Udaipur City, India. Self-administered structured questions were used to assess their educational achievements, career aspirations and oral hygiene behavior (OHB). Achievement motives were assessed using Achievement Motive Scale developed by Lang and Fries (2006). Chi-square test and multivariate logistic regression tests were used in data analysis. Confidence level and level of significance were set at $95 \%$ and $5 \%$ respectively.

RESULTS: Students with better educational achievements undergone regular dental check-up (30.48\%) $(p=0.03)$ and used other oral hygiene aids (90.24\%) ( $p=0.01)$. Tooth brushing frequency, time and replacement time of tooth brush were found to be significantly associated with career aspiration ( $p=0.007$; $p=0.002 ; p=0.00$ respectively). Achievement motives did not have statistically significant association with oral hygiene behavior.

CONCLUSION: Educational achievements and career aspirations appear to be associated with oral hygiene behavior of young dental students. Students with higher career aspirations practiced better oral hygiene behavior. There was no significant relationship between achievement motives and oral hygiene behavior.

KEY WORDS: Educational achievements, career aspirations, achievement motives, oral hygiene.
\end{abstract}

DOI: http://dx.doi.org/10.4314/ejhs.v24i4.3

\section{INTRODUCTION}

Motives for choosing a career are complex, and the choice of a career in dentistry is not an exception. Many factors may enter into the career choice(1): perceptions of one's own strengths and weaknesses, interests and desires, the willingness and financial security to undergo the lengthy period of training associated with particular careers, the actual type of work that a particular career entails, the working conditions or the availability and attractiveness of alternative careers. In recent years, a number of studies have investigated the motivations underlying the career choice of dental students (2-6).

There is a well-established association between health behaviors and the education of adolescents (7, 8). A cross-national survey on the health behavior of 11 year old schoolchildren in 22 European countries and in Canada found that the association between oral hygiene behaviors and education was not universal(9).

\footnotetext{
${ }^{1}$ Department of Public Health Dentistry, Pacific Dental College \& Hospital, Debari, Udaipur, Rajasthan, India

${ }^{2}$ Department of Public Health Dentistry, Rama Dental College and Hospital, Kanpur, UP, India

Corresponding Author: Kailash Asawa, Email: kailashasawaudr@yahoo.com
} 
Several studies showed that new students all over the world are usually faced with a dilemma in making a career choice decision in their lives (10-15). In most cases, the choice of careers, subjects and the subsequent career paths to follow is a nightmare for prospective undergraduate students (12). This can also be explained by the child's career aspirations. Individuals who have better Sense of Coherence are more optimistic towards their life (16).

Human beings have the tendency to engage themselves in various activities to find out if they can survive and perform under such conditions. They usually have either an acceptance or an avoidance tendency towards a particular goal. Such achievement motive behavior can be related to the excellence of the individual. Lang and Fries (2006) established a scale based on achievement motives known as Achievement Motive Scale. The approach tendency is labeled as 'hope of success' and the avoidance tendency is called 'fear of failure' (17). It was revealed that individuals who brushed their teeth more than twice a day reported higher values of hope of success than individuals who reported their tooth brushing frequency to be once a day or less(18).

Hygiene is defined as the practice of keeping oneself and one's surroundings clean (19). One of the primary goals of dental health professionals is to prevent oral diseases. Oral hygiene is often related to optimism and satisfaction in life (20). There is also a social gradient in oral hygiene practice in adolescents, i.e. those from a higher social status are more likely to practice oral hygiene (21).

Thus, the objective of this study was to investigate whether educational achievements, career aspirations and achievement motives have an association with oral hygiene behavior among dental students of Udaipur, India.

\section{MATERIALS AND METHODS}

Study design and population: A descriptive cross sectional study was conducted during the month of August 2013 among all $1^{\text {st }}$ year dental students $(n=200)$ from both dental colleges [Pacific Dental College and Hospital $(n=100)$ and Darshan Dental College and Hospital $(n=100)]$ in Udaipur city, Rajasthan, India.

Ethical approval and official permission: The study protocol was reviewed by the Ethical Committee of Pacific Dental College and Hospital and was granted ethical clearance. An official permission was obtained from the principals of both dental colleges respectively.
Informed consent: after examining the purpose and details of the study, a written informed consent was obtained from all the subjects who were willing to participate.

Pre-testing of questionnaire: A structured questionnaire was administered to a convenient sample of 20 first year dental students who were interviewed to gain feedback on the overall acceptability of the questionnaire in terms of conceptual clarification and feasibility of administration. However, the questionnaire did not require any correction. Cronbach's coefficient was found to be 0.85 , which showed an internal reliability of the questionnaire. Face validity was also assessed and it was observed that $92 \%$ of the participants found the questionnaire to be easy. Mean Content Validity Ratio (CVR) was calculated as 0.87 based on the opinions expressed by a panel of six academicians.

The samples within the pilot study were excluded from the main study. So, the final sample size was achieved to be 180 .

Details of the questionnaire: The questionnaire consisted of demographic information and questions regarding educational achievements, career aspirations, achievement motives and oral hygiene behavior. Educational achievements were assessed by the percentage of marks attained by the students in previous year examinations. Another question was concerned about career aspirations with different options (post-graduation, private practice, government job, going abroad, leaving dentistry and joining some other profession or doing nothing). Achievement motives were assessed using Achievement Motive Scale developed by Lang and Fries (2006). A set of questions also solicited information about the oral hygiene behaviors like tooth brushing, dental visits and other oral hygiene aids used.

The participant's responses were ranked according to various options given to them for each question. Questions regarding achievement motives were ranked with alternatives: Agree or Disagree.

Statistical analysis: Completed questionnaires were coded and spread sheets were created for data entry. The data was analyzed using SPSS 19 (SPSS Inc. Chicago, IL, USA) Windows software program. The responses of the oral hygiene behavior dimension of the questionnaire were dichotomized. Descriptive statistics were used to summarize the demographic information. Data regarding educational achievement and career aspirations were analyzed using the chisquare test. Multivariate logistic regression was used to consider association between the dependent and 
independent variables. Confidence level and level of significance was fixed at $95 \%$ and $5 \%$ respectively.

\section{RESULTS}

A total of 200 first year dental students participated in the study. Demographic data showed that majority of the respondents were females $(n=168$ [84\%]) and in high socio-economic status group $(n=151$ [75.5\%]). The percentage of study population with career aspirations of doing post-graduation after Forty one percent of study population had scored more than $60 \%$ in their success $(n=199$ [99.5\%]) and lower fear of failure $(n=197$ [98.5\%]) (Table 1).

Table 1: Distribution of study subjects according to several independent variables

\begin{tabular}{|c|c|c|}
\hline $\begin{array}{l}\text { Variables } \\
\text { Sex }\end{array}$ & Number (n) & Percentage $(\%)$ \\
\hline Male & 32 & 16 \\
\hline Female & 168 & 84 \\
\hline \multicolumn{3}{|c|}{ Socio-economic status } \\
\hline Low & 1 & 0.5 \\
\hline Medium & 48 & 24 \\
\hline High & 151 & 75.5 \\
\hline \multicolumn{3}{|l|}{ Career aspiration } \\
\hline Post-Graduation & 67 & 33.5 \\
\hline Private practice & 83 & 41.5 \\
\hline Govt. job & 0 & 0 \\
\hline Abroad & 26 & 13 \\
\hline Leave dentistry & 24 & 12 \\
\hline Doing nothing & 0 & 0 \\
\hline \multicolumn{3}{|c|}{ Educational achievements } \\
\hline$<50 \%$ & 52 & 26 \\
\hline $50-59 \%$ & 66 & 33 \\
\hline $60-74 \%$ & 82 & 41 \\
\hline \multicolumn{3}{|c|}{ Achievement motives } \\
\hline \multicolumn{3}{|l|}{ Hope of success } \\
\hline $0-2$ & 1 & 0.5 \\
\hline $3-5$ & 199 & 99.5 \\
\hline \multicolumn{3}{|l|}{ Fear of failure } \\
\hline $0-2$ & 197 & 98.5 \\
\hline $3-5$ & 3 & 1.5 \\
\hline Total & 200 & 100 \\
\hline
\end{tabular}

Higher proportion of females in the study population $(\mathrm{n}=168)$ responded more appropriately to the questions regarding oral hygiene behavior than males. However, there was no statistically significant difference between males and females. Higher socio-economic status was associated with better oral hygiene behavior. Significantly, greater proportion of subjects in higher socio-economic status group brushed their teeth twice daily (73\%) $(\mathrm{p}=0.002)$ and for $2-3$ minutes duration $(96.68 \%)$ $(\mathrm{p}=0.005)$. Students aspiring for post-graduation and private practice after graduation were more likely to have better oral hygiene behavior compared to other career ambitions. Tooth brushing frequency, time and replacement time of tooth brush were found to be significantly associated with career aspiration $(\mathrm{p}=0.007$; $p=0.002 ; p=0.00$ respectively). Majority of those 
who secured better marks $(>60 \%)$ undergone regular (every 6 months) dental check-up (30.48\%) $(\mathrm{p}=0.03)$ and used other oral hygiene aids $(90.24 \%) \quad(p=0.01) . \quad$ Regarding achievement motives, there was no statistically significant association seen with oral hygiene behavior. However, it was found that those having higher hope of success and lower fear of failure had better oral hygiene behavior compared to others (Table 2).

Table 2: Assessment of oral hygiene behavior with several independent variables

\begin{tabular}{|c|c|c|c|c|c|c|c|}
\hline Variables (n) & $\begin{array}{l}\mathrm{TB} \geq 2 \\
\text { daily } \\
\text { n }(\%)\end{array}$ & $\begin{array}{l}\text { TB for } \\
\text { 2-3 min } \\
n(\%)\end{array}$ & $\begin{array}{l}\text { Correct } \\
\text { TB } \\
\text { method } \\
\text { n }(\%)\end{array}$ & $\begin{array}{l}\text { Tooth brush } \\
\text { bristles } \\
\text { Soft/medium } \\
\text { n }(\%)\end{array}$ & $\begin{array}{l}\text { Replacing } \\
\text { tooth brush } \\
\text { as soon as } \\
\text { bristles } \\
\text { fray out } \\
\text { n }(\%)\end{array}$ & $\begin{array}{l}\text { Regular } \\
\text { dental } \\
\text { check-up } \\
\text { n }(\%)\end{array}$ & $\begin{array}{lr}\text { Use } & \text { of other } \\
\text { oral } & \text { hygiene } \\
\text { aids } & \\
\text { n }(\%) & \end{array}$ \\
\hline \multicolumn{8}{|l|}{ Sex } \\
\hline Male (32) & $12(37.5)$ & $29(90.62)$ & $24(75)$ & $20(62.5)$ & $16(50)$ & $11(34.37)$ & $25(78.12)$ \\
\hline Female (168) & $72(42.85)$ & $158(94.04)$ & $141(83.92)$ & $86(51.19)$ & $90(53.57)$ & $42(25)$ & $145(86.30)$ \\
\hline p-value & 0.57 & 0.47 & 0.22 & 0.24 & 0.84 & 0.28 & 0.77 \\
\hline \multicolumn{8}{|l|}{ Socio-economic status } \\
\hline Low (1) & $1(100)$ & $1(100)$ & $1(100)$ & $1(100)$ & $0(0)$ & $0(0)$ & $1(100)$ \\
\hline Medium (48) & $10(20.83)$ & $40(83.33)$ & $37(77.08)$ & $27(56.25)$ & $22(45.83)$ & $10(20.83)$ & $46(95.83)$ \\
\hline High (151) & $73(48.34)$ & $146(96.68)$ & $127(84.10)$ & $78(51.65)$ & $84(55.62)$ & $43(28.47)$ & $123(81.45)$ \\
\hline p-value & $0.002 *$ & $0.005^{*}$ & 0.48 & 0.54 & 0.28 & 0.48 & 0.66 \\
\hline \multicolumn{8}{|l|}{ Career aspiration } \\
\hline Post-Graduation (67) & $38(56.71)$ & $58(86.56)$ & $62(92.53)$ & $35(52.23)$ & $17(25.37)$ & $17(25.37)$ & $55(82.08)$ \\
\hline Private practice (83) & $24(28.91)$ & $81(97.59)$ & $64(77.10)$ & $45(54.21)$ & $60(72.28)$ & $18(21.68)$ & $71(85.54)$ \\
\hline Govt. job (0) & $0(0)$ & $0(0)$ & $0(0)$ & $0(0)$ & $0(0)$ & $0(0)$ & $0(0)$ \\
\hline Abroad (26) & $12(46.15)$ & $24(92.30)$ & $21(80.76)$ & $16(61.53)$ & $15(57.69)$ & $12(46.15)$ & $24(92.30)$ \\
\hline Leave dentistry (24) & $10(41.66)$ & $24(100)$ & $18(75)$ & $10(41.66)$ & $14(58.33)$ & $6(25)$ & $22(91.66)$ \\
\hline Doing nothing $(0)$ & $0(0)$ & $0(0)$ & $0(0)$ & $0(0)$ & $0(0)$ & $0(0)$ & $0(0)$ \\
\hline p-value & $0.007 *$ & $0.02 *$ & 0.06 & 0.55 & $0.00 *$ & 0.10 & 0.54 \\
\hline \multicolumn{8}{|c|}{ Educational achievements } \\
\hline$<50 \%(52)$ & $17(32.69)$ & $50(96.15)$ & $48(92.30)$ & $32(61.53)$ & $28(53.84)$ & $18(34.61)$ & $46(88.46)$ \\
\hline $50-59 \%(66)$ & $34(51.51)$ & $59(89.39)$ & $53(82.81)$ & $28(42.42)$ & $34(51.51)$ & $10(15.15)$ & $50(75.75)$ \\
\hline $60-74 \%(82)$ & $33(40.24)$ & $78(95.12)$ & $64(78.04)$ & $46(56.09)$ & $44(53.65)$ & $25(30.48)$ & $74(90.24)$ \\
\hline $\mathrm{p}$-value & 0.11 & 0.24 & 0.09 & 0.09 & 0.95 & $0.03 *$ & $0.01 *$ \\
\hline \multicolumn{8}{|l|}{ Achievement motives } \\
\hline \multicolumn{8}{|l|}{ Hope of success } \\
\hline $0-2(1)$ & $1(100)$ & $1(100)$ & $1(100)$ & $1(100)$ & $0(0)$ & $0(0)$ & $1(100)$ \\
\hline 3-5 (199) & $83(41.70)$ & $186(93.45)$ & $164(82.41)$ & $105(52.76)$ & $106(54.92)$ & $53(26.63)$ & $169(84.92)$ \\
\hline p-value & 0.42 & 1.00 & 1.00 & 1.00 & 0.47 & 1.00 & 1.00 \\
\hline \multicolumn{8}{|l|}{ Fear of failure } \\
\hline 0-2 (197) & $83(42.13)$ & $184(93.40)$ & $162(82.23)$ & $105(53.29)$ & $105(53.29)$ & $53(26.90)$ & $167(84.77)$ \\
\hline $3-5(3)$ & $1(33.33)$ & $3(100)$ & $3(100)$ & $1(33.33)$ & $1(33.33)$ & $0(0)$ & $3(100)$ \\
\hline p-value & 1.00 & 1.00 & 1.00 & 0.60 & 0.60 & 0.56 & 1.00 \\
\hline Total & $84(42)$ & $187(93.5)$ & $165(82.5)$ & $106(53)$ & $106(53)$ & $53(26.5)$ & $170(85)$ \\
\hline
\end{tabular}

Statistical test applied: chi-square., *statistically significant difference at $\mathrm{p} \leq 0.05$

$\mathrm{TB}=$ Tooth brushing

Table 3 depicts the findings of multivariate logistic regression analyses with odds ratios $(95 \% \mathrm{CI})$. Students in middle socio-economic status group were less likely to brush their teeth than other group of students $(\mathrm{OR}=0.37, \quad \mathrm{CI}=0.16-0.85$, $\mathrm{P}<0.05)$ and less likely to spend enough time on their daily tooth brushing $(\mathrm{OR}=8.73, \mathrm{CI}=1.98$ -
38.42, $\mathrm{P}<0.05$ ) with delayed time of replacement of tooth brush $(\mathrm{OR}=0.53, \mathrm{CI}=0.20-0.99, \mathrm{P}<0.05)$. On the other hand, students with ambitions of postgraduation after completion of their graduation had better oral hygiene behavior. They showed better understanding of tooth brushing method $(\mathrm{OR}=0.24, \mathrm{CI}=0.06-0.97, \mathrm{P}<0.05)$ and when $\mathrm{a}$ 
Table 3: Multiple logistic regression: Odds ratios (95\% CI) for oral hygiene behavior by independent variables

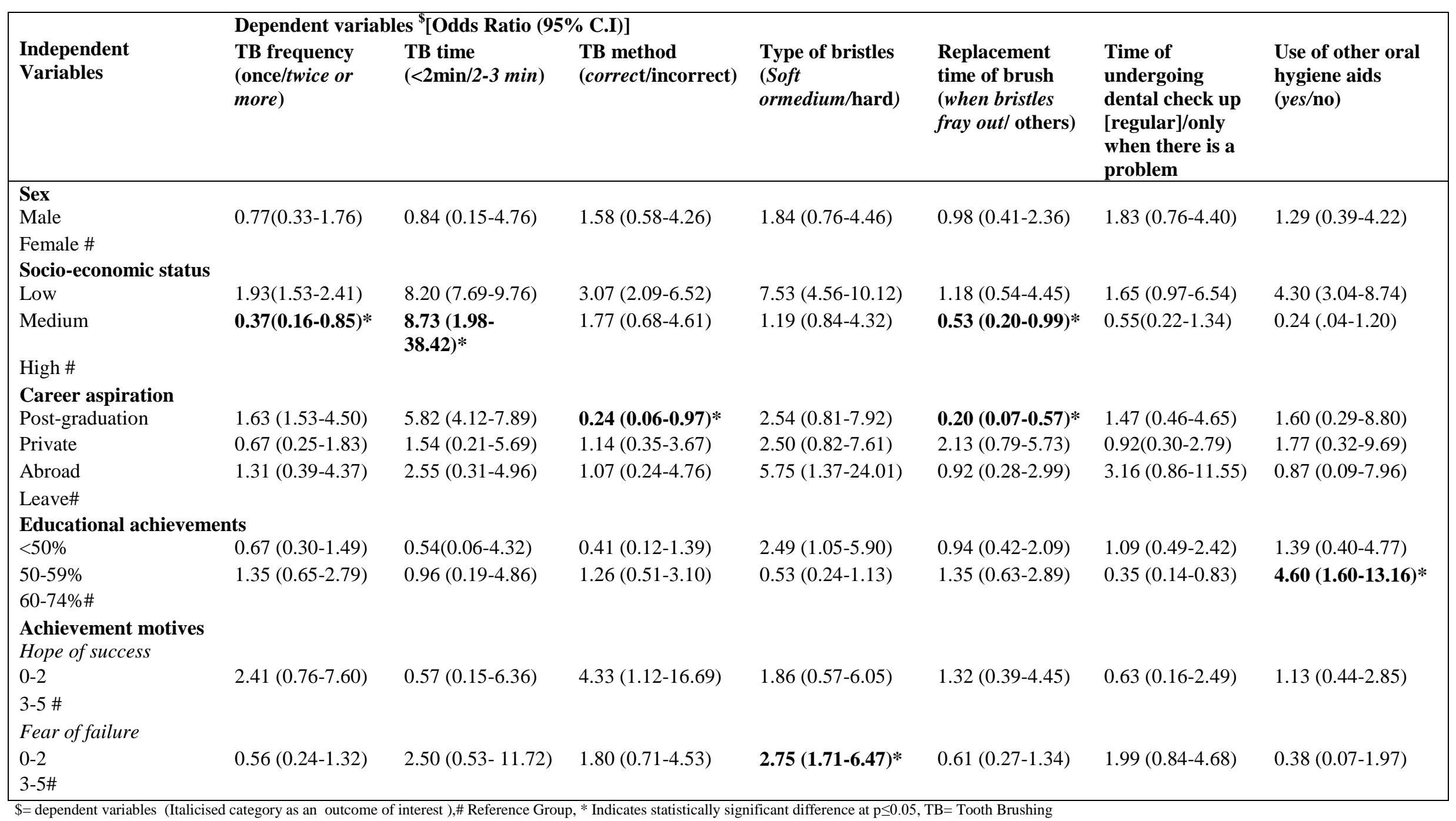


tooth brush needs to be replaced $(\mathrm{OR}=0.20, \mathrm{CI}=$ 0.07-0.57, $\mathrm{P}<0.05)$ compared to other groups. Also, students with previous marks in the range of 50\%$59 \%$ had lower understanding of oral hygiene behavior compared to those who scored higher. However, they had better understanding of oral hygiene aids used $(\mathrm{OR}=4.60, \mathrm{CI}=1.60,13.16$, $\mathrm{P}<0.05)$ than those students who scored less than $50 \%$. Regarding the achievement motives, more optimistic students showed better oral hygiene status $(\mathrm{OR}=2.75, \quad \mathrm{CI}=1.71-6.47, \quad \mathrm{P}<0.05) \quad$ compared to those with higher fear of failure.

\section{DISCUSSION}

This study was conducted on 200 first year dental students of Udaipur to find out the association between educational achievements, career aspirations, achievement motives and oral hygiene behavior. To the best of our knowledge, this is the first study to examine the relationship of educational achievements, career aspirations and achievement motives with oral hygiene behavior of young Indian dental students.

In our study, females responded more appropriately to the questionnaire as compared to males. However, we did not find any significant difference in the oral hygiene behavior of females and males which is in agreement with the findings of Khami et al in 2007 and Casanova-Rosado JF et al. in 2013 (22, 23). In contrast, Al-Wahadniet al (24) and Petersen et al. (25) established that females had better oral hygiene behavior than males. Also, Kuusela $\mathrm{S}$ et al. and Al-Omari et al. $(9,27)$ explained better awareness among females regarding oral hygiene habits. In the present study, most of the students were from business class families but with low to medium parental education level. Thus, lack of motivation and awareness regarding oral hygiene behavior might be the reason for this negative association. Also, the influence of hormonal changes in females along with multiple social and religious factors may have contributed to their deprived oral hygiene behavior.

Social background is an important factor influencing the development of oral hygiene behavior and the educational achievements of an individual. Adolescents with a better social background (e.g. higher parental education level and higher annual income) benefit from an environment consisting of values, social support and social resources, which enhances educational achievement and oral healthrelated behaviors, including oral cleanliness and tooth brushing $(28,29)$. They have more confidence in the success of their children in challenging and demanding tasks (25). We found a considerably fair oral hygiene behavior among the students of higher socio-economic group compared to other groups. The frequency of tooth brushing and tooth brushing time was found to be better than other groups, which is in agreement with the findings from previous studies that highlighted the influence of family social class on their dental behaviors $(26,30,31)$. Besides, those who were good in studies achieved better oral hygiene behavior status than others relating to the fact that education influences the oral hygiene of an individual in a positive manner. This assumption is supported by findings from another study which indicated that education influences hygiene behaviors in adolescents through its impact on Sense of Coherence and peer social networks (32).

Those with career aspirations of doing postgraduation or setting up their own dental practice after graduation were found to have better oral hygiene behavior than other career ambitions. This can be correlated with the fact that post-graduation or setting up their own dental practice are considered to be the most acceptable career options after graduation in India which requires consistent studies and dedication to achieve the desired goals. These can be correlated with the findings by Garrahy et al. in 2001 (33) and Falaye and Adams in 2008 (34) which stated that better future aspirations resulted in better vision of knowledge and better understanding of the importance of oral hygiene. Also, the urge to face career challenges that are congruent with aptitude and abilities of the student results in motivated oral hygiene behavior which is in agreement with the findings of the previous studies $(33,34)$.

Achievement motive is understood as a generalized evaluative and behavioral tendency in situations where this standard of excellence can be applied. Previous studies have positively associated oral hygiene behavior and achievement motives of an individual $(34,35)$. In our study, however, we did not find any difference in achievement motives among students with optimistic and pessimistic view of life. This might be attributed to the active coping mediator between oral hygiene behavior and optimism (35). The adjustment of this mediating mechanism is believed to cause the negative association between achievement motives and oral hygiene behavior. Thus, further studies are required to offer a new insight into oral hygiene behavior.

The present study surveyed all first year dental students from both dental colleges in Udaipur with a $100 \%$ response rate. They do not have enough knowledge about proper oral hygiene behavior and the awareness regarding the same is just par with other students. Moreover, previously calibrated 
Achievement Motive Scale (Lang and Fries, 2006) (17) was used along with self-administered questions. These were calibrated and validated for the present study population. This increases the internal validity of the study. Hence, the results of the study may be generalized to other college-going students.

The assessment of oral hygiene behavior was based on students self-report. A number of steps were taken to maximize the reliability of the students selfreport on different study-outcome variables. Questionnaires were administered in both institutions by the same researcher to provide a more comfortable environment for the students in which to answer the questions. Moreover, no information was gathered regarding their names so as to maintain the confidentiality of their responses. The students were assured that their responses would be solely used for this research. The limitation of the present study is that we are not sure how truthfully and thoughtfully the respondents answered the questionnaire.

Thus, it is concluded that educational achievements and career aspirations seem to be associated with oral hygiene behavior of young dental students. Higher education leads to better oral hygiene behaviors. Students who have higher career ambitions and future aspirations practice better oral hygiene behavior. There was no significant relationship found between achievement motives and oral hygiene behavior. Thus, future studies should be conducted and an objective clinical assessment should be carried out in the field.

\section{ACKNOWLEDGEMENTS}

The authors would like to thank the study participants for their participation and kind cooperation throughout the study. We thank all the members who contributed to this project and sincerely acknowledge their efforts in complying with the requirements of the study.

\section{REFERENCES}

1. Gati I, Osipow SH, Givon M. Gender differences in career decision making: the content and structure of preferences. $J$ CounsPsychol 1995;42(2): 204-216.

2. Zadik D, Gilad R, Peretz B. Choice of dentistry as a career and perception of the profession. $J$ Dent Educ 1997;61: 813-816.

3. Brand A A, Chitke U M E, Thomas C J. Choosing dentistry as a career-a profile of entering students (1992) to the university of
Sydney, Australia. Aust Dent J 1996;41: 198205.

4. Lawson W R. The choice of dentistry as a career. N Z Dent J 1976;72:155-158.

5. Gietzelt D. Social profile of first-year dentistry students at the University of Sydney. Aust Dent $J$ 1997;42:259-266.

6. Rice C D, Glaros A G, Shouman R, Hlavacek M. Career choice and occupational perception in accelerated option and traditional dental students. J Dent Educ 1999;63:354-358.

7. West P. Rethinking the health selection explanation for health inequalities. SocSci Med 1991;32:373-384.

8. Blumenshine SL, Vann WF, Gizlice Z, Lee JY. Children's school performance: impact of general and oral health. J Public Health Dent 2008;68: 82-87.

9. Kuusela S, Honkala E, Kannas L, Tynjala J, Wold B. Oral hygiene habits of 11-year-old schoolchildren in 22 European countries and Canada in 1993/1994. J Dent Res 1997;76: 1602-1609.

10. Bandura A, Barbaranelli C, Caprara GV, Pastorelli C. Self-efficacy beliefs as shapers of children's aspirations and career trajectories. Child Development 2001;72:187-206.

11. Cherian VI. Parental aspirations and academic achievement of Xhosa children. Psychological Reports 1991;68:547-553.

12. Issa AO, Nwalo KIN. Factors Affecting the Career Choice of Undergraduates in Nigerian Library and Information Science Schools. African Journal of Library, Archives and Information Science 2008;18(1):23-32.

13. Macgregor K. South Africa: Student Dropout Rates Alarming in SA Universities. University World News, South Africa2008:34.

14. McMahon M, Watson M. Occupational information: What children want to know? Journal of Career Development 2005;31:239249.

15. Watson M, McMahon M, Foxcroft C, Els C. Occupational aspirations of low socio-economic Black South African children. Journal of Career Development 2010;37(4):717-734.

16. Antonovsky A. Unraveling the mystery of health. How people manage stress and stay well. Jossey Bass, San Francisco1987:1.

17. Lang JWB, Fries S. A revised 10-item version of the achievement motives scale. Eur J Psychol Assess 2006;22:216-224. 
18. Dumitrescu AL, Kawamura M, Dogaru BC, Dogaru CD. Relation of achievement motives, satisfaction with life, happiness and oral health in Romanian university students. Oral Health Prev Dent 2010;8(1):15-22.

19. Boot M, Cairncross S. Action Speak: the study of hygiene behaviour in water and sanitation projects. IRC International water and sanitation centres, The Hague 1993.

20. Arrindell WA, Heesink JA, Feij JA. The satisfaction with life scale (SWLS): appraisal with 1700 healthy young adults in The Netherlands. PersIndividDif 1999;26:815-826.

21. Lopez R, Fernandez O, Baelum V. Social gradients in periodontal diseases among adolescents. Community Dent Oral Epidemiol 2006; 34: 184-196.

22. Khami MR, Virtanem JI, Jafarian M, Murtomaa H. Prevention- oriented practice of Iranian senior dental students. Eur J Dental Educ 2007;11:48-53.

23. Casanova-Rosado JF, Vallejos-Sánchez AA, Minaya-Sánchez M et al. Frequency of tooth brushing and associated factors in Mexican school children six to nine years of age. West Indian Med J 2013;62 (1):68-72.

24. Al-Wahadni A M, AL-Omiri M K, Kawamura M. Differences in self-reported oral health behavior between dental students and dental technology/dental hygiene students in Jordan. $J$ Oral Sci 2004;46:191-197.

25. Petersen PE, Peng B, Tai B, Bian Z, Fan M. Effect of a school-based oral health education programme in Wuhan City, Peoples' Republic of China. Int Dent J 2004;54:33-41.

26. Al-Omari QD, Hamasha AA. Gender-Specific Oral Health Attitudes and Behavior among Dental Students in Jordan. J Contemp Dent Pract 2005;6:107-114.
27. Erikson R, Jonsson JO. Explaining class inequality in education: the Swedish test case. In: Erikson R, Jonsson JO, eds. Can education be equalized? The Swedish case in comparative perspective. Westview, Oxford 1996:1-63.

28. Koivusilta LK., Rimpela AH, Rimpela M., Vikat A. Health behavior-based selection into educational tracks starts in early adolescence. Health Educ. Res 2001;16 (2):201-214.

29. Albandar JM. Global risk factors and risk indicators for periodontal diseases. Periodontol 2000 2002;29: 177-206.

30. Albandar JM, Tinoco EMB. Global epidemiology of periodontal diseases in children and young persons. Periodontol 2000 2002;29:153-176.

31. Dorri M, Sheiham A, Hardy R, Watt R. The relationship between Sense of Coherence and toothbrushing behaviors in Iranian adolescents in Mashhad. J ClinPeriodontol 2010;37:46-52.

32. Garrahy DA. Three third-grade teachers' gender related beliefs and behaviors. The Elementary School Journal 2001;102(1): 81-94.

33. Falaye FW, Adams BT. An assessment of factors influencing career decisions of in-school youths. Pakistan Journal of Social Sciences 2008;5(3):222- 225.

34. Honkala S, Honkala E, Al-Sahli N. Do life- or school satisfaction and self-esteem indicators explain the oral hygiene habits of schoolchildren? Community Dent Oral Epidemiol 2007;35:337-347.

35. Ylöstalo PV, Ek E, Knuuttila ML. Coping and optimism in relation to dental health behavior a study among Finnish young adults. Eur J Oral Sci 2003;111:477-482. 